are anxious to have them-surely, therefore, the Council would be justified in having them reprinted; the branch secretaries conld easily learn the number in their respective districts, of those who wish for copies, and then forward the list to the Council, who could thus determine whether the expense of reprinting would he covered, and, if so, I hope they will publish Sydenham's works in the manner you advise.

I am, Sir, your most obedient servant,

Glasgow, March 12, 1845.

A General Practitioner.

THE LECTURES AT ST. GEORGE'S. To the Editor of THE LANCET.

SrR,-I was surprised on reading in your last number the charges laid against Mr. James Johnson. I infer that the writer could not be a pupil of Kinnerton-street, otherwise he would have known better than to say that Mr. Johnson invariably lectures a quarter of an hour less that Mr. Tatum. Mr. Johnson and his colleague both begin and end at the same hour, the lecture terminating at half-past three. Mr. Johnson is, perhaps, five minutes behind his time at commencing, but he makes up for it at the conclusion, for he makes a point of not leaving off in the middle of a subject. So that, in most cases, he finishes his lecture at twenty or twenty-five minutes to four As for the frequency of his commencing his lecture at three or five minutes to three, I can only say that such an occurrence happened but once, when a very good reason was assigned for his being so tardy. Of course, in a case requiring operation, Mr. Johnson, or any other lecturer, would be warranted in postponing the lecture, as a man's life is (I think you will grant me) of more consequence than a lecture upon physiology. Trusting you see the justice of my remarks,

$$
\text { Believe me, yours truly, }
$$

Kinnerton-street, March 15, 1845.

A PUPR. R.

We have received another letter, since the above was in type, from a pupil of Kinnerton School, denying, in the strongest terms, that any blame can be imputed to Mr. Johnson.

\section{OFFICIAL ANSWERS TO QUERIES RESPECTING REGISTRATION.}

To the Editor of THE LANCET.

Sin,-At the request of the committee of medical gentlemen, for whom we act, we beg to inclose a copy of queries on the construction of clause 32 of Sir James Graham's new Bill, and of the replies courteously given thereto by the Home Office.

As the subject of the status of the present general practitioner ander the new Bill is exciting much interest and discussion, and the riew generally taken by the profession is contrary to that just received from an official quarter, we hope you will readily give insertion to the papers.

We remain, Sir, your obedient servants, $\left.\begin{array}{l}\text { Henny Cooper, M.D. } \\ \text { Robert P. HeIght, }\end{array}\right\}$ Hon. Secs.

Hull, March 20, 1845.

$$
\left.\begin{array}{l}
\text { Henry Cooper, M.D. } \\
\text { Robert P. Height, }
\end{array}\right\} \text { Hon. Secs. }
$$

At a meeting of a committee appointed by a general meeting of the profession, to watch proceedings, held March 11th, 1845, it was resolved to request replies from the Home Office to the two following questions:-

1. Can any gentleman now practising as a member of the Royal College of Surgeons and licentiate of the Apothecaries' Company, (dispensing his own medicines and practising midwifery,) register as "surgeon" under the new Act?

2. Can such a practitioner register both as "surgeon" and as "licentiate of medicine and surgery" under the new Act?

To these questions the following answer was returned:Whitehall, March 17, 1843

Gentlemer, - I am directed by Secretary Sir James Graham to acknowledge the receipt of your letter of the 12 th instant, and to inform you, that under the Bill for the Regulation of Medical Practice, a gentleman at present practising as a member of the Royal College of Surgeons and licentiate of the Apothecaries Company, (dispensing his own medicines and practising midwifery, can register as surgeon.

The Bill does not contemplate double registry.

The registered surgeon may practise generally, if he pleases. I am, Gentlemen, your obedient servant, S. M. Prinlipps.

\section{EDINBURGH GRADUATES UNDER THE NEW BILL.}

Since the publication of our last number, Dr. Fergusson, of Bath, has received from the Right Honourable the Secretary of State the following answer to the queries which we then published. To make it quite intelligible, we reprint the queries:-

1. Will the graduates in medicine of the University of Edinburgh, now in possession of their diploma, simply as such, on producing them to the Council of Health, be allowed to register as legal physicians?

2. Or will it also be necessary for such graduates to become fellows, associates, or licentiates, of some college of physicians, or of that college of physicians of that division of the kingdom in which they reside, and if such connexion with a college of physicians is obligatory on them, will any fee of admission be demanded, and of what amount?

Whitehall, March 18th, 1845.

Srn,- I am directed by Secretary Sir James Graham to acknowledge the receipt of your letter of the $7 \mathrm{th}$ instant, respecting the Bill for regulating the practice in medicine \&c., and to acquaint you, in answer to query one in your letter, that graduates in medicine of the University of Edinburgh, now in possession of their diplomas, will, on producing them, be allowed to register as physicians. With respect to your second query, I am to answer it in the negative. And I am to observe for your consideration, whether you are aware that your practice in England as physician, without the licence of the Physicians' College, you not being a graduate of Oxford or Cambridge, is now illegal, and that the Bill will make it legal.

I am, Sir, your obedient servant,

(Signed) S. M. PhILlipps.

\section{DR. AYRES ON THE DETECTION OF ARSENIC.}

To the Editor of THE LA NCET.

Str,-Will you have the kindness to insert the following process for detecting arsenic, in an early number of your journal. The process depends on the conversion of arsenious into arsenic acid, by the action of chlorine on arsenious acid in solution. I do not remember to have seen any statement that arsenious acid takes another equivalent of oxygen when chlorine is passed into its solution; but as so many observations are published at the present time, and as it is almost impossible to keep up with the progress of chemistry, such an observation may have been previously made. Let this be as it may, I will now give the details of a process, by which one-hundredth of a grain, or even less, of arsenious acid may be detected in solution in water.

I took half a grain of arsenious acid, placed it in two ounces of water, and passed a current of chlorine through the liquid, until the whole of the arsenious acid disappeared. Each drachm of the liquid then contained $\frac{1}{32} \mathrm{nd}$ of a grain of arsenious acid, which, by the action of chlorine, was converted into arsenic acid. One drachm was evaporated to dryness, and the residue, re-dissolved in a few drops of water, gave, when treated with ammoniacal nitrate of silver, a copious brick-red precipitate of arseniate of silver.

A'second drachm was treated in a similar manner, but re-dissolved in three drachms of distilled water. Of these three drachms of solution, one was taken and treated with the ammoniacal nitrate, when a distinct precipitate of arseniate of silver fell. As a drachm of the original liquid was equivalent to $\frac{1}{3} \overline{2}$ nd of a grain of arsenious acid, one-third of this quantity must be equivalent to only $\frac{1}{96}$ th of a grain; and as the precipitate was still very distinct, $I$ doubt not that, with very great care, $\frac{3}{150}$ th, or even $\frac{x}{200}$ th of a grain may be detected in this manner.

I have not yet had time to test the process in organic liquids, but I hope to do so within a few days, and will then communicate the result of my researches to your readers.

I have every reason to believe that this will be found a great improvement in testing for arsenic in organic fluids, because many organic matters are either rendered insoluble or decomposed by chlorine, and at the same time the arsenious is converted into arsenic acid, which is exceedingly soluble and less volatile than arsenious acid.

If the reduction process be required, the arsenic acid is easily reduced, as in the process of Varentrapp and Woll, by the addition of sulphurous acid, which reduces the arsenic to arsenious acid, and the excess of which may be easily expelled by boiling the liquid, after which the sulphuret may be thrown down by sulphuretted hydrogen, and the usual reduction process performed. I am, Sir, your obedient servant,

Ph. B. A rres, M.D. Lond.,

Lecturer on Chemistry, Charing-Cross Hospital.

Howland-street, Fitzroy-square, March 20th, 1845. 